http://jmscr.igmpublication.org/home/ ISSN (e)-2347-176x ISSN (p) 2455-0450

crossref DOI: https://dx.doi.org/10.18535/jmscr/v9i12.19

\title{
Outcome of Minimally Invasive Plate Osteosynthesis in Distal Tibial Fractures
}

\author{
Authors \\ Kiran Gurung $^{{ }^{*}}$, Vinod Kumar Thapa ${ }^{2}$, Prakash Bahadur Thapa ${ }^{3}$ \\ ${ }^{1}$ Orthopedic Surgeon, Western Hospital Pvt. Ltd., Nepalgunj, Nepal \\ ${ }^{2} \mathrm{HoD}$, Department of Orthopedics, Bheri Hospital, Nepalgunj, Nepal \\ ${ }^{3}$ Orthopedic Surgeon, Bheri Hospital, Nepalgunj, Nepal \\ *Corresponding Author \\ Dr Kiran Gurung \\ Orthopedic Surgeon \\ Western Hospital Pvt. Ltd., Nepalgunj, Nepal
}

\begin{abstract}
Introduction: Unstable fractures of the distal tibia with or without intra-articular extension can present a clinical dilemma. Historically, there have been a variety of methods of management described but with high rates of associated complications. Minimally Invasive Plate Osteosynthesis (MIPO), has now become more in demand with the development of the Locking Compression Plates. MIPO offers many biological superiorities including minimal soft tissue dissection with preservation of vascular integrity of the fracture as well as preserving osteogenic fracture hematoma.

Materials and Methods: A total of 30 patients with distal tibia fractures (open/closed) were included in the study after informed consent. Patients were treated by MIPO and were prospectively followed up. Duration of follow-up ranged from 3-6 months. Demographic variables, mode of injury, time required for union, complications and clinical improvement were recorded and analyzed.

Results: Most of the fractures were united by 4 months (83.3\%) with a mean union time of $4.26 \pm 0.98$ months. Excellent clinical results with MIPO were observed in $66.7 \%$ of cases while poor results were obtained in $6.7 \%$ of cases. Complications were seen in 15 subjects (50\%), of which most common was wound infection, seen in $66.6 \%$ of the cases.

Conclusion: MIPO is an effective technique in the management of distal tibial fractures. It is minimally invasive, though technically demanding, but saves the biological environment by preserving the soft tissue with better outcomes in terms of radiological union and clinical improvement.
\end{abstract}

Keywords: Distal tibial fractures, MIPO, intramedullary nailing.

\section{Introduction}

Distal tibia fractures occurred in patients commonly as a result of a force directed from the foot towards the leg in high energy traumatic events, such as falling down, traffic accident, motorcycle accident, or sport injury ${ }^{(1)}$.

Considering the need for anatomical reduction and rigid internal fixation sometimes, it might be necessary to widely expose the surrounding 
tissues of the fracture, which could cause delayed union or nonunion owing to over-destruction of soft tissue and blood supply around the fracture ${ }^{(2)}$. The common surgical procedures included intramedullary nailing, minimally invasive plate osteosynthesis (MIPO), open reduction and internal fixation (ORIF), and external fixation.

In recent years, intramedullary nails were widely used because of their successful outcomes and minimal damage to bone and soft tissue, especially in open fractures ${ }^{(3)}$. Some researchers reported that intramedullary nailing was an effective technique for stabilizing distal tibia ${ }^{(4,5)}$. However, delayed bone healing, reoperation, and a high incidence of primary and secondary malalignment have also been reported, especially in distal and proximal tibial fractures, which may associated with the large cavity ${ }^{(6)}$.

The treatment of distal tibial fractures with plate provided a reliable fixation by achieving anatomical reduction and restoring alignment of the limb, which could allow early rehabilitation exercise for patients. But the high incidence of wound problems and reoperation was also reported $^{(7)}$. With the development of minimally invasive technology, minimally invasive plate osteosynthesis (MIPO) has become an excellent method $^{(8)}$. It protected the subcutaneous soft tissue of anterior medial tibia and enabled adequate soft tissue coverage overlying the plate with less wound complications ${ }^{(9,10)}$.

In this backdrop, the present study was conducted to evaluate the functional and radiological outcome of distal tibia fractures treated 'by minimally invasive plate osteosynthesis

\section{Materials and Methods}

A total of 30 patients with distal tibia fractures satisfying inclusion criteria admitted to the Department of Orthopedics, Bheri Hospital, Nepalganj were included in the study after informed consent.

Duration of follow-up ranged from 12-24 weeks. Demographic variables, mode of injury, time required for union, complications and clinical improvement were recorded. The fractures were classified according to AO/OTA classification system $^{(11)}$.

\section{Inclusion Criteria}

1) Patient $>18$ years.

2) Closed and Open tibia type I and II fractures.

3) Intra-articular extension of the fracture.

\section{Exclusion Criteria}

1) Pathological fractures.

2) Patients with co-morbid conditions posing a risk for surgery.

\section{Pre-Operative Regimen}

The patients were resuscitated in the emergency room and a complete examination of the patient for other associated injuries was done. Neurological and vascular assessment of the involved limbs was carried out. Wound lavage, dressing and splintage was done as per the initial assessment and injury to the patient. Analgesics, Antibiotics, I.V fluids were administered as per protocol and tetanus prophylaxis as per requirement was given. Basic blood parameters were evaluated. Gram positive and gram negative antibiotic cover was given for closed fractures. Anaerobic antibiotic cover was given to patients with open fractures along with the above mentioned antibiotics. The patients were taken for surgery after initial resuscitation, stabilization of vital parameters and after getting pre anesthetic check-up and clearance. Surgical techniques Once the patient was prepared and draped, intraoperative antibiotics were given before the inflation of tourniquet. By traction and manipulation reduction was tried. The provisional reduction was then confirmed by image guidance under C-ARM (IITV). After adequate reduction and alignment is achieved plate size was selected under image guidance so as to provide adequate fixation and stabilization of fracture. In MIPPO technique, incision was made obliquely at the tip of medial malleolus and extended proximally to create easy passage. The medial malleolus was exposed, with care taken to protect the great saphenous vein. Percutaneous elevators were then 
inserted to create a submuscular, extraperiosteal tunnel for the plate. The passage of the plate till fracture site was confirmed with C-ARM imaging. An incision was made proximally at the approximate proximal edge of the plate. The anterior and posterior borders of the medial tibia were then palpated, and incision was extended longitudinally exposing the periosteum. Submuscular plane was developed in proximal incision and tunnel developed till fracture site and the plate was pushed by the surgeon's opposite hand. The plate was palpated in the proximal incision and confirmed to be well seated. The plate was then fixed on the tibial surface with a Kirschner wire inserted through a fixation bolt. Adequate positioning was then confirmed with anteroposterior and lateral imaging. The proximal position of the plate was then checked to ensure central placement of the tibial shaft (using the CArm). This was then followed by insertion of fixation screws following the standard procedure for non-locking cortical screws and locking screws. All the non locking screws were inserted first as decided pre-operatively and after attaining adequate reduction, locking screws were inserted. A minimum of four screws were used in each main fragment of the fracture. After the plate was inserted with the screws, the stabilization bolt was removed from the middle distal hole and a screw was inserted in its place. The principles of fixation using LCP were followed to at every stage of fixation. This was followed by irrigation of all the incisions with normal saline and wound closure in layers. The technical problems/ complications during the procedure (if any) was recorded

\section{Post operative regimen}

Post operative X-ray was done to document proper reduction and fixation of fracture fragments. Ankle mobilization was started from 2nd or 3rd post operative day according to the forbearance of patients or associated injuries. Antibiotics (Intravenous /oral) were continued till the wound condition necessitates. Progressive weight bearing was permitted according to the callous formation as assessed in follow up $\mathrm{X}$
Rays. Regular follow up of the patients was done in OPD with X-rays and evaluation of functional outcome. All long-term complications like nonunion, malunion, angular deformity, implant breakage, shortening or infection were recorded. The patients were followed up till the bony union of the fracture / up to 6 months, whichever was earlier. The final results were based on the functional and radiological outcomes. Operated patients were followed up using OLERUD and MOLANDER scoring system and the final results were graded as: excellent/good/fair/poor ${ }^{[14]}$

\section{Results}

In our study there were 22 males and 8 females, ranging in age from 25 to 65 years, with an average age of $43.76 \pm 5.67$ years. The duration of follow up was 3 months to 6 months. Most of the patients in our study group were below 50years, and the most common mode of injury was Road Traffic Accidents. Majority of the patients were male $(73.3 \%)$ and $(26.7 \%)$ were females. 20 patients had right side injury and 10 patients had left side injury.

Table 1 shows Distribution of patients based on $\mathrm{AO} / \mathrm{OTA}$ Classification. Among the 30 patients, majority of them had A1 classification 18 (60\%).

Table 1: Patients distribution based on the AO/ OTA Classification

\begin{tabular}{|l|c|c|}
\hline $\begin{array}{l}\text { AO/ OTA } \\
\text { Classification }\end{array}$ & No of Patients & $\begin{array}{c}\text { Percentage } \\
(\%)\end{array}$ \\
\hline $\mathrm{A} 1$ & 18 & 60 \\
\hline $\mathrm{A} 2$ & 4 & 13.3 \\
\hline $\mathrm{A} 3$ & 6 & 20 \\
\hline $\mathrm{B} 1$ & 2 & 6.7 \\
\hline Total & 100 & 100 \\
\hline
\end{tabular}

Majority of the patients, $25(83.3 \%)$ displayed union in 4 months and the mean union time was $4.26 \pm 0.98$ months. The results were shown in table 2 .

Table 2: Fracture union time among the study participants

\begin{tabular}{|l|c|c|}
\hline Union Time (Months) & No of patients & Percentage (\%) \\
\hline$<3$ & 2 & 6.7 \\
\hline $4-5$ & 25 & 83.3 \\
\hline 6 & 3 & 10 \\
\hline
\end{tabular}


Excellent clinical results with MIPO were observed in 20 patients $(66.7 \%)$ while poor results were obtained in $2(6.7 \%)$ patients. The results were shown in table 3 .

Table 3: Clinical outcome of the study participants

\begin{tabular}{|l|c|c|}
\hline Clinical Outcome & No of Patients & Percentage \\
\hline Excellent & 20 & 66.7 \\
\hline Good & 4 & 13.3 \\
\hline Fair & 4 & 13.3 \\
\hline Poor & 2 & 6.7 \\
\hline
\end{tabular}

Complications were seen in 15 subjects (50\%) and the most common was wound infection in 10 patients, Malunion was observed in 2 patients and 3 patients displayed ankle stiffness. The results were shown in table 4.

Table 4: Complication among the patients undergoing MIPO

\begin{tabular}{|l|c|c|}
\hline Complication & No of Patients & Percentage \\
\hline Wound infection & 10 & 66.7 \\
\hline Malunion & 2 & 13.3 \\
\hline Ankle Stiffness & 3 & 20 \\
\hline Total & 15 & 100 \\
\hline
\end{tabular}

\section{Discussion}

Distal tibia fracture with or without intra articular extension is one of the difficult fractures to manage. None of the treatment options available exquisitely fulfill the requirements of fracture characteristics of distal tibia. Distal tibia has got circular cross sectional area with thinner cortex as compare to triangular diaphysis with thicker cortex. So, intramedullary nail which is designed for tight interference fit at diaphysis cannot provide same stability at distal fracture ${ }^{(12)}$. Other potential complications of nailing are malunion $(0-29 \%)$ and implant failure $(5-39 \%)^{(12)}$. ORIF with conventional plate which needs striping of periosteum is also not an ideal treatment option because tibia is subcutaneous bone and periosteum provides $2 / 3$ rd of blood supply. Non union, delayed union and infection are reported with the range of $8.3-35 \%$ and $8.3-25 \%$ respectively with ORIF with plating ${ }^{(13)}$. Similarly, external fixators as a definitive method of treatment for distal diametaphyseal tibia fracture are also reported with higher rate of infection, implant failure and malunion or nonunion and hence recommended only for temporary method of stabilization in open fracture with severe soft tissue injury ${ }^{(14)}$. With the development of technique of MIPO with LCP which preserve extraosseous blood supply, respect osteogenic fracture haematoma, biologically friendly and stable fixation method is available for distal diametaphyseal tibia fracture. Indirect reduction method and sub-cutaneous tunneling of the plate and application of locking screws with small skin incisions in MIPO technique prevents iatrogenic injury to vascular supply of the bone ${ }^{(15)}$. Unlike conventional plates, LCP is a friction independent self stable construct which provides both angular and axial stability and minimizes risk of secondary loss of reduction through a threaded interface between the screw heads and the plate body.

Comparative studies with IMIL or conventional open techniques have found conflicting results with MIPO with LCP for distal diametaphyseal tibia fracture. Vallier et al. $^{(16)}$ reported significantly more angular malalignment in distal diametaphyseal tibia fracture, treated with IMIL in comparison to those treated with plating (22 patients vs 2 patients, $p=0.003$ ) whereas Guo et al. (17) in a comparative study of extra articular distal diametaphyseal tibia fracture reported that patients treated with IMIL nailing had better function, alignment and American Orthopedic Foot Ankle score, though none of them were statistically significant. Cheng et al. in a small sampled paired comparison (15 in each group) of MIPO and open technique with LCP found former is not statistically better in terms of union time (16.8 vs., 19.2 wks, $\mathrm{p}=0.737)$, recovery time to return to work ( 21.1 vs. 27.7 weeks, $\mathrm{p}=0.35)$ and functional results $^{(18)}$. Kao et al. found no statistically significant advantages of LCP over conventional plate group (19). Although the use of MIPO with LCP as internal external fixators, anatomical reduction of the fracture by using indirect reduction maneuvers before applying the plate is very important surgical step. Malreduction and 
suboptimal pre contouring of the plate can result delayed union, non union, prominent hardware, malleolar skin irritation and pain.

Indirect reduction of fracture under $\mathrm{C}$ arm control can be difficult at time. Various reduction maneuvers such as calcaneal pin traction, external fixators or mechanical distractors have been described to achieve reduction ${ }^{(20)}$. MIPO technique can restore alignment in high velocity distal diametaphyseal tibia fracture and patients can expect predictable return of function. However, Collinge et al. reported increased secondary procedure rate like bone grafting for delayed union ${ }^{(21)}$. Rate of secondary procedures like iliac crest bone grafting or per cutaneous bone marrow injection for delayed union or non union or change of hardware has been reported $3.8 \%$ to as high as up to $35 \%{ }^{(21)}$. The average time for fracture union in the present study is also comparable to other studies ${ }^{(22)}$.

Reported rate of wound infection varies between $2.6 \%$ to $14.6 \%$ depending upon whether open fracture are included in the study or not ${ }^{(22)}$. The present study which included both types of fractures found wound infection in 10 cases. Three patients who had superficial wound infection improved with antibiotics but patient with wound breakdown and exposed implant had protracted post operative rehabilitation period requiring repeated wound debridement and long hospital stay.

\section{Conclusion}

MIPO is an effective minimally invasive technique for the management of distal tibial fractures. It is technically demanding, but preserves the biological environment by preserving the soft tissue with better outcome in terms of radiological union and clinical improvement

\section{References}

1. Vaienti E, Schiavi P, Ceccarelli F, Pogliacomi F. Treatment of distal tibial fractures: prospective comparative study evaluating two surgical procedures with investigation for predictive factors of unfavourable outcome. Int Orthop, 2019, 43: 201-207.

2. Yang KH, Won Y, Kang DH, Oh JC, Kim SJ. Role of appositional screw fixation in minimally invasive plate Osteosynthesis for distal Tibial fracture. J Orthop Trauma, 2015, 29: e331-e335.

3. Wang Z, Cheng Y, Xin D, et al. Expert Tibial nails for treating distal Tibial fractures with soft tissue damage: a patient series. J Foot Ankle Surg, 2017, 56: 1232 1235.

4. Levin PE. Intramedullary nailing of periarticular fractures. J Orthop Trauma, 2013, 27: e125.

5. Triantafillou K, Barcak E, Villarreal A, Collinge C, Perez E. Proper distal placement of Tibial nail improves rate of malalignment for distal tibia fractures. $\mathbf{J}$ Orthop Trauma, 2017, 31: e407-e411.

6. Pairon P, Ossendorf C, Kuhn S, Hofmann A, Rommens PM. Intramedullary nailing after external fixation of the femur and tibia: a review of advantages and limits. Eur J Trauma Emerg Surg, 2015, 41: 2538.

7. Piatkowski K, Piekarczyk P, Kwiatkowski K, Przybycien M, Chwedczuk B. Comparison of different locking plate fixation methods in distal tibia fractures. Int Orthop, 2015, 39: 2245-2251.

8. He X, Hu C, Zhou K, Zhai Q, Wen W, Pan F. Clinical and radiological outcome of Gustilo type III open distal tibial and tibial shaft fractures after staged treatment with posterolateral minimally invasive plate osteosynthesis (MIPO) technique. Arch Orthop Trauma Surg, 2018, 138: 10971102.

9. Devkota P, Khan JA, Shrestha SK. Minimally invasive plate osteosynthesis for distal tibial fractures. J Orthop Surg (Hong Kong), 2014, 22: 299-303. 
10. Ehlinger M, Adam P, Bonnomet F. Minimally invasive locking screw plate fixation of non-articular proximal and distal tibia fractures. Orthop Traumatol Surg Res, 2010, 96: 800-809.

11. Swiontkowski MF, Agel J, McAndrew MP, Burgess AR, MacKenzie EJ. Outcome validation of the AO/OTA fracture classification system. Journal of orthopaedic trauma. 2000 Nov 1;14(8):534-41.

12. Kneifel T, Buckley R. A comparison of one versus two distal locking screws in tibial fractures treated with unreamed tibial nails: a prospective randomized clinical trial. Injury. 1996; 27:271-273

13. Yang SW, Tzeng HM, Chou YJ, Teng HP, Liu HH, Wong CY. Treatment of distal tibial metaphyseal fractures: Plating versus shortened intramedullary nailing. Injury. 2006; 37:531-535.

14. Joveniaux $P$, Ohl $X$, Harisboure A, Berrichi A, Labatut L, Simon P, Mainard D, Vix N, Dehoux E. Distal tibia fractures: management and complications of 101 cases. Inter Orthop. 2010; 34:583-88.

15. Borrelli J, Prickett W, Song E, Becker D, Ricci W. Extra osseous blood supply of the distal tibia and the effects of different plating techniques: Human cadaveric study. J Orthop Trauma. 2002;16: 691-95

16. Vallier HA, Le TT, Bedi A. Radiographic and clinical comparisons of distal tibia shaffractures (4 to $11 \mathrm{~cm}$ proximal to the plafond): plating versus intramedullary nailing. J Orthop Trauma. 2008;22:307-11.

17. Guo JJ, Tang N, Yang HL, Tang TS. A prospective, randomised trial comparing closed intramedullary nailing with percutaneous plating in the treatment of distal metaphyseal fractures of the tibia. $\mathrm{J}$ Bone Joint Surg Br. 2010; 92-B:984-8

18. Cheng W, Li Y, Manyi W. Comparison study of two surgical options for distal tibia fracture-minimally invasive plate osteosynthesis vs. open reduction and internal fixation. Int Orthop. 2011 May;35(5):737-42.

19. Kao FC, Tu YK, Hsu KY, Wu CH, Yen $\mathrm{Cy}$, Chou MC. Treatment of distal tibial fractures by minimally invasive percutaneous plate osteosynthesis of three different plates: Results and costeffectiveness analysis. Formosan $\mathbf{J}$ Musculoskeletal Disorders. 2010; 1:35-40

20. Shanmugam C, Rahmatalla A, Maffulli N. Percutaneous fixation of distal tibial fractures using locking plates. Tech Orthop. 2007; 22(3):162-6

21. Collinge C, Kuper M, Larson K, Protzman R. Minimally invasive plating of high energy metaphyseal distal tibia fractures. J Orthop Trauma. 2007; 21:355-61

22. Shrestha D, Acharya BM, Shrestha PM. Minimally invasive plate osteosynthesis with locking compression plate for distal diametaphyseal tibia fracture. Kathmandu Univ Med J. 2011;34(2)62-8. 